Fidel de la Garza

\title{
DEPRESIÓN EN LA INFANCIA Y ADOLESCENCIA.
}

Editorial Trillas

2007

Teresita M. Duarte Buitrón*

rubioduarte9@hotmail.com

A continuación se realiza una breve reseña de los temas y conceptos más importantes que el autor trabaja en el texto, se espera que éstos sean de utilidad para quien o quienes desean dedicarse a tratar con pacientes que presentan estos trastornos.

\section{CAPÍTULO I. Causas de la Depresión.}

Entre las causas de la depresión que el autor señala en este capítulo están las siguientes:

1. La genética. Con respecto a este punto, el autor señala que los factores genéticos pueden incrementar el riesgo de depresión y los hijos de padres y madres depresivas tienen seis veces más riesgo de padecerla.

2. Las alteraciones químicas. Se ha encontrado en pacientes depresivos una falta de balance en la comunicación de sustancias (neurotrasmisores) particularmente en: la serotonina, la noreprinefrina y la dopamina, estos son los más estudiados hasta el momento.

3. La depresión materna durante el embarazo o en los primeros años de vida del niño. Define evento vital a las circunstancias del ambiente que pueden potencialmente alterar el bienestar físico o mental del niño y que disparan o dan comienzo a un periodo depresivo. Hay cuatro tipos de eventos: 1. El peligro hacia la persona. 2. Peligro hacia otros. 3. Decepciones Personales. 4. Pérdidas.

4. La influencia de los eventos tempranos en la vida del niño. Estos eventos pueden 0 no provocar depresiones posteriores, no todas las personas manejamos adecuadamente estas experiencias y posteriormente afectan de manera considerable la vida de las mismas.

5. Depresión y ambiente. El ambiente y diferentes eventos que pueden o no desencadenar este problema.

6. El niño con pensamientos depresivos. Las características de un niño con pensamientos depresivos y de qué manera éstos influyen en su actuar cotidiano.

\section{Capítulo II. EL NIÑO CON PENSAR DEPRESIVO.}

En este capítulo, el autor establece que nuestra realidad es construida por nuestros pensamientos y la forma en cómo interpretamos lo que nos pasa.

Aquello que pensamos de la vida determina lo que sentimos y por lo tanto, lo que vamos a hacer o hacemos.

$Y$ si pensamos en forma negativa, generalmente nos ponemos tristes y nos comportamos como una persona depresiva. Todos estos pensamientos irracionales son 
adoptados por el sujeto y provoca que se menosprecie y visualice el futuro y por supuesto se vean las cosas de manera pesimista y se hagan juicios equivocados de las cosas e inclusive de las personas.

Este patrón de pensamientos tiende a producir sentimientos de desesperanza, ya que hay una tendencia a ver el vaso medio vacío en lugar de medio lleno.

\section{¿Cómo influye la visión de sí mismo?}

El estilo de pensar depresivo refleja un bajo sentido de autoestima y desesperanza, sin embargo, aunque la forma de pensar es factor importante para la depresión, no es factor casual suficiente por sí mismo, puesto que el estrés de la vida juega un papel importante en el inicio y mantenimiento de la depresión.

\section{Estilos de personalidad relacionados con la depresión:}

Sentirse desamparado, con temor al abandono y necesidad extrema de cuidado y amor y la otra personalidad es la tendencia a sentirse culpable y con sentimientos de menor valía y de que no se alcanza lo esperado.

El niño o joven con depresión tiene pensamientos negativos de sí mismo y el cerebro reacciona promoviendo cambios químicos hacia la depresión.

El autor menciona que los pensamientos depresivos más frecuentes son:

- Yo soy una persona inferior a otras.

- Me va mal en la escuela, no sirvo.

- Soy tonto.

- Nadie me quiere.

- Mis amigos me rechazan porque soy desagradable,

- Soy feo o gordo y no soy atractivo.

- Quisiera morirme.

- Quisiera caerle bien a los demás y no puedo.

- No puedo vivir sin ella o sin él.

- Me voy a volver loco, me siento mal.

- Decepciono a mis padres con mi forma de ser.

- Las cosas no cambian, todo sigue igual.

En el capítulo IV el autor habla acerca del tratamiento para la depresión en niños y adolescentes, destaca el papel fundamental que tiene la familia en estos pacientes. La colaboración de los padres es crucial, la conducta de los padres es un moderador en la respuesta terapéutica de los niños, la presencia de los padres sirve como un apoyo en la 
educación psicológica de sus hijos, por último, la inclusión de los padres en el tratamiento es una invitación para preservar y mejorar las relaciones y los vínculos que se han formado a lo largo de la vida.

Por otro lado, hace mención del manejo de los antidepresivos en el tratamiento de pacientes depresivos y de cómo estos pueden ser un factor de riesgo si no son utilizados adecuadamente.

El capítulo V plantea la idea de cómo luchar contra el pensamiento depresivo, y menciona a la terapia cognitiva como la más efectiva a largo plazo, y no sólo el tratamiento a base de depresivos. Existen estudios que comprueban la efectividad de la terapia cognitiva con o sin fármacos que con la medicación sola.

El capítulo VI Luchando contra la depresión y las drogas. Actualmente el alcohol es utilizado por una inmensa mayoría de jóvenes y $30 \%$ de los adolescentes han utilizado algún tipo de droga para sentirse menos tristes o para tratar de evadir su realidad, con resultados, desde luego, funestos.

Nunca hay que olvidar, nos dice el autor, que el uso de drogas y alcohol produce depresión. Al principio, el primer efecto puede ser euforizante, pero por lo general, los pacientes depresivos tienen al día siguiente un aumento de tristeza. Así que el autor establece una serie de recomendaciones para luchar en contra de la depresión y del uso y abuso de cualquier droga o tipo de alcohol.

En el capítulo VII el autor aborda el tema del suicidio en los jóvenes, explica qué tan frecuente es la conducta suicida, y sus posibles causas, los métodos más frecuentes utilizados en ello, los tipos de suicidio, y los factores de riesgo que incrementan su potencia entre sí y los múltiples factores que pueden precipitar el suicidio así como las consecuencias que trae éste en la familia cuando alguien se suicida.

En el capítulo VIII La escuela y la depresión infantil se habla de cómo los síntomas depresivos alteran la vida escolar, el pensamiento se altera y se vuelve lento, la angustia, la timidez, la inasistencia a la misma, los pensamientos tristes, entre otros, alteran de manera importante el interés por la escuela y se comienzan a manifestar conductas como el aislamiento, desinterés, rebeldía, indiferencia, entre otros. $Y$ un aspecto muy importante, es el de cómo identificar a los niños en riesgo.....aspecto muy importante para tomar decisiones y evitar mayores problemas.

Por último, en el capítulo IX Medios de comunicación, trata acerca de ¿qué influencia tiene la televisión sobre los niños depresivos? Y establece que ésta tiene el potencial de generar efectos negativos y positivos sobre ellos.

Aunque no todos los programas son malos como lo establece el autor, hay una grave exposición a la violencia, a la sexualidad inapropiada y a escuchar un lenguaje ofensivo. La televisión limita el tiempo dedicado a actividades como jugar, leer, aprender a hablar, compartir con la familia y amigos y practicar ejercicio y deportes, así como desarrollar habilidades físicas, mentales y sociales. 
Trata acerca de cómo influyen los anuncios publicitarios, el Internet, los videojuegos y expresa una serie de recomendaciones para padres y madres de familia sobre todo de niños y jóvenes vulnerables a este problema.

\section{COMENTARIO PERSONAL.}

En general, considero este texto de gran utilidad para quienes desean saber acerca de los diversos factores que inciden en la depresión en la infancia y la adolescencia. El autor maneja con claridad conceptos relacionados con el tema y establece de la misma manera las causas, efectos y tratamiento para ello. Desde luego, hay temas y conceptos en los que amplía más la información de los mismos, como por ejemplo el trastorno bipolar y de atención e hiperactividad (pág.59) el trastorno obsesivocompulsivo (pág. 69) entre otros.

Este es un tema que en la actualidad se escucha con mayor frecuencia, tanto en el ámbito familiar, como el escolar y social, por lo que considero necesario estar bien informado y conocer cuáles son las principales causas de estos problemas, sus consecuencias y los posibles tratamientos para ayudar a estas personas a superarlo. 